\title{
Bilateral multiple pulmonary artery aneurysms associated with cavitary pulmonary tuberculosis: a case report
}

Pedro Pallangyo ${ }^{1 *}$, Frederick Lyimo², Smita Bhalia ${ }^{1}$, Hilda Makungu ${ }^{2}$, Bashir Nyangasa $^{3}$, Flora Lwakatare ${ }^{2}$, Pal Suranyi ${ }^{4}$ and Mohamed Janabi ${ }^{1}$

\begin{abstract}
Background: Pulmonary artery aneurysms constitute $<1 \%$ of aneurysms occurring in the thoracic cavity. Congenital cardiac defects are responsible for the majority $(>50 \%)$ of cases, however, pulmonary artery aneurysm is a rare sequelae of pulmonary tuberculosis reported in about $5 \%$ of patients with chronic cavitary tuberculosis on autopsy. The natural history of this potentially fatal condition remains poorly understood and guidelines for optimal management are controversial.

Case presentation: A 24-year-old man, a nursing student of African descent, was referred to us from an upcountry regional hospital with a 4-week history of recurrent episodes of breathlessness, awareness of heartbeats and coughing blood 3 weeks after completing a 6 -month course of anti-tuberculosis drugs. A physical examination revealed conjuctival and palmar pallor but there were no stigmata of connective tissue disorders, systemic vasculitides or congenital heart disease. An examination of the cardiovascular system revealed accentuated second heart sound $\left(S_{2}\right)$ with early diastolic (grade 1/6) and holosystolic (grade 2/6) murmurs at the pulmonic and tricuspid areas respectively. Blood tests showed iron deficiency anemia, prolonged bleeding time, and mild hyponatremia. A chest radiograph revealed bilateral ovoid-shaped perihilar opacities while a computed tomography scan showed bilateral multiple pulmonary artery pseudoaneurysms with surrounding hematoma together with adjacent cystic changes, consolidations, and tree-in-bud appearance. Our patient refused to undergo surgery and died of aneurismal rupture after 9 days of hospitalization.

Conclusions: The presence of intractable hemoptysis among patients with tuberculosis even after completion of antituberculosis course should raise an index of suspicion for pulmonary artery aneurysm. Furthermore, despite of its rarity, early recognition and timely surgical intervention of pulmonary artery aneurysm is crucial to reducing morbidity and preventing the attributed mortality.
\end{abstract}

Keywords: Pulmonary artery aneurysm, Pulmonary hypertension, PA aneurysm, PAA, tuberculosis, TB

\section{Background}

Focal dilatation $(>4 \mathrm{~cm})[1-3]$ of the pulmonary arterial system is referred to as pulmonary artery aneurysm (PAA). Owing to its asymptomatic course in the majority of cases, this rare entity used to be an autopsy finding with prevalence rates ranging between $0.001 \%$ and $0.007 \%$ [4-7]. With the advent of a two-dimensional (2D)-echocardiography

\footnotetext{
* Correspondence: pedro.pallangyo@gmail.com

'Department of Cardiovascular Medicine, Jakaya Kikwete Cardiac Institute,

P.O Box 65141, Dar es Salaam, Tanzania

Full list of author information is available at the end of the article
}

(ECHO), computed tomography (CT) scan and magnetic resonance imaging (MRI), more cases are now diagnosed often incidentally among living patients [8-13]. Nonetheless, the natural history of this potentially fatal condition remains poorly understood and guidelines for optimal management are controversial [3, 14-18].

Causes of PAA are numerous and diverse in pathogenesis, however, congenital cardiac defects (patent ductus arteriosus, ventricular and atrial septal defects) are implicated in about $50 \%$ of cases $[19,20]$. Other causes include infections (tuberculosis, syphilis, mycotic aneurysms), 
systemic vasculitides (Behcet's disease, giant cell arteritis), connective tissue disorders (Marfan's syndrome, HughesStovin syndrome), degenerative diseases (atherosclerosis), chest trauma, and idiopathic PAA [3, 4, 8, 9, 14, 16-24]. The clinical manifestations of PAA are largely nonspecific but dyspnea, palpitations, chest pain, cough, and hemoptysis are frequently reported in symptomatic patients [1-28]. Radiological imaging is essential in establishing the diagnosis as the nonspecific clinical findings are inevitably inconclusive. We report a case of bilateral multiple pulmonary artery aneurysms in a 24-year-old male nursing student from Tanzania.

\section{Case presentation}

A 24-year-old man, a nursing student of African descent, was referred to us from an up-country regional hospital for further investigations and expert management. His past medical history was unremarkable and he denied any history of tobacco or intravenous drug use (IVDU), chest trauma, sexually transmitted infection (STI) or open tuberculosis (TB) contact. He was diagnosed with pulmonary $\mathrm{TB}$ based on constitutional symptoms and chest X-ray findings, and had completed a 6-month course of anti-TB medications (isoniazid, rifampicin, pyrazinamide, and ethambutol) 7 weeks prior his visit to our institution. He was somewhat symptom-free for about 3 weeks when he developed recurrent episodes of breathlessness, awareness of heartbeats and coughing blood, which had gradually worsened and persisted for about 4 weeks prior this index visit.

On examination, he was a sick-looking but oriented and well-kempt young man. He had a blood pressure of $92 / 57 \mathrm{mmHg}$, pulse rate of 121 beats/minute, respiratory rate of 19 breaths/minute and temperature of $36.7{ }^{\circ} \mathrm{C}$. His body mass index (BMI) was $21.2 \mathrm{~kg} / \mathrm{m}^{2}$ (weight 59 $\mathrm{kg}$ and height $1.67 \mathrm{~m}$ ). A physical examination revealed conjuctival and palmar pallor but there were no stigmata of connective tissue disorders, systemic vasculitides or congenital heart disease. A respiratory system examination revealed bilateral symmetrical chest movements; however, dullness and reduced breath sounds were noted on the mammary and inframammary regions bilaterally on percussion and auscultation respectively. An examination of the cardiovascular system revealed accentuated second heart sound $\left(\mathrm{S}_{2}\right)$ with early diastolic (grade $1 / 6$ ) and holosystolic (grade 2/6) murmurs at the pulmonic and tricuspid areas respectively.

Hematological and biochemical tests revealed iron deficiency anemia [hemoglobin $(\mathrm{Hb}) 8.18 \mathrm{~g} / \mathrm{dL}$, mean corpuscular volume (MCV) $61.8 \mathrm{fL}$, mean corpuscular hemoglobin $(\mathrm{MCH}) 19.2 \mathrm{pg} / \mathrm{cell}$ and red cell distribution width (RDW) $21.9 \%$ ], prolonged bleeding time [prothrombin time (PT) $14.6 \mathrm{~s}$ and partial thromboplastin time (PTT) 32.7 s], and mild hyponatremia [sodium concentration $\left.\left(\mathrm{Na}^{+}\right) 132 \mathrm{mmol} / \mathrm{L}\right]$. Serological tests for human immunodeficiency virus (HIV), hepatitis B and $\mathrm{C}$, and syphilis were all negative. Moreover, occult blood test was negative and an abdominal ultrasonography scan was unremarkable. A sputum culture revealed Pseudomonas aeruginosa $3++$ sensitive to ciprofloxacin and gentamicin. A chest X-ray showed bilateral, ovoidshaped perihilar opacities extending to lower lung zones with loss of silhouette sign on the left cardiac border (Fig. 1). An electrocardiogram (ECG) displayed a sinus tachycardia while echocardiography (ECHO) was evident for right ventricular hypertrophy, mild tricuspid regurgitation with estimated right ventricular systolic pressure (RVSP) of $29 \mathrm{mmHg}$ (that is, mild pulmonary hypertension) and multiple focal dilatations along the right and left pulmonary arteries. Systolic functions were, however, preserved (ejection fraction 53\%). A GeneXpert test was positive. A computed tomography (CT) scan of his chest showed bilateral multiple pulmonary artery pseudoaneurysms with surrounding hematoma together with adjacent cystic changes, consolidations and tree-in-bud appearance (Figs. 2, 3, 4, and 5). The aneurysms on the right pulmonary artery measured $3.81 \times 2.55 \mathrm{~cm}$ and $6.96 \times 5.34 \mathrm{~cm}$ whereas those on the left measured $2.61 \times 2.03 \mathrm{~cm}, 6.85 \times 4.45 \mathrm{~cm}$ and $7.05 \times 4.03 \mathrm{~cm}$ respectively. His main pulmonary artery $(2.55 \mathrm{~cm})$, ascending $(2.28 \mathrm{~cm})$, arch $(1.89 \mathrm{~cm})$, and descending aorta $(2.00$ $\mathrm{cm}$ ) had normal caliber and dimensions. We entertained a diagnosis of bilateral multiple pulmonary pseudoaneurysms associated with cavitary pulmonary tuberculosis and admitted him to the general medical ward. Intravenous ciprofloxacin $500 \mathrm{mg} 12$ hourly, bisoprolol 5 mg once daily, tadalafil $(40 \mathrm{mg})$ and ferrous sulfate (270

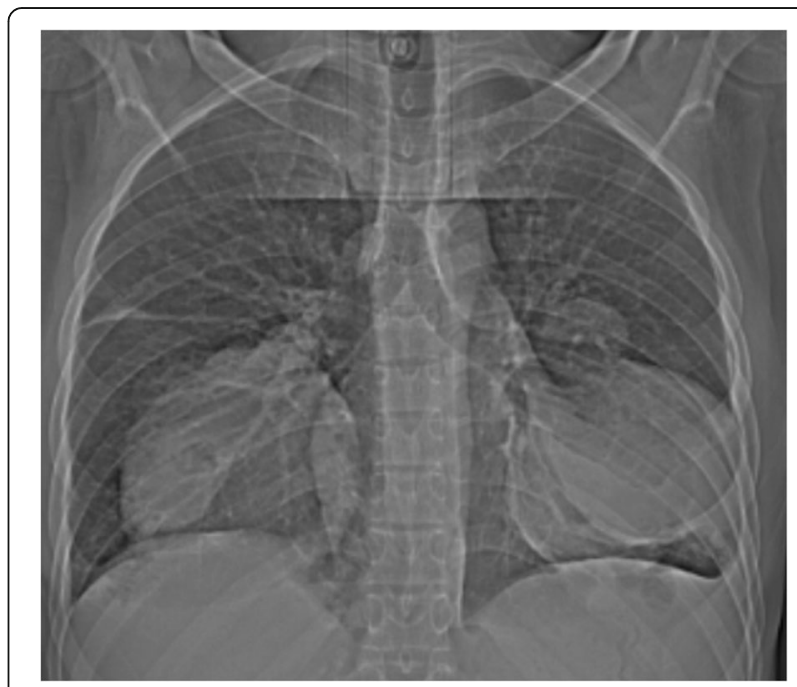

Fig. 1 Chest X-ray (posteroanterior view) displaying bilateral, ovoidshaped perihilar opacities extending to lower lung zones with loss of silhouette sign on the left cardiac border 


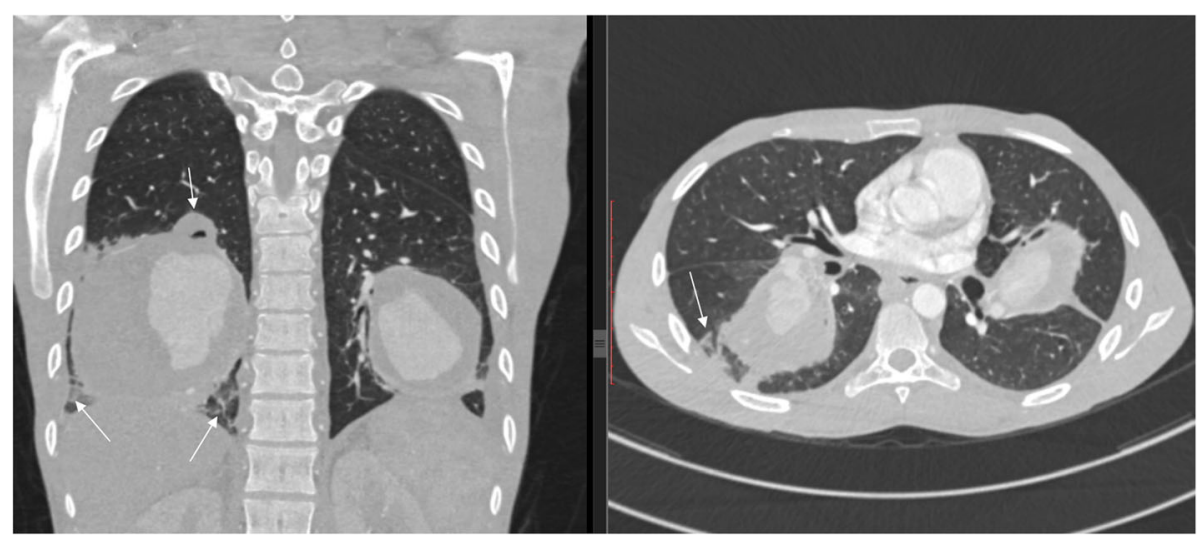

Fig. 2 Computed tomography chest scan (coronal and axial views) showing bilateral pulmonary artery pseudoaneurysms with adjacent cystic changes (arrows), consolidations and tree-in-bud appearance

mg) plus folic acid (300 mcg) were initiated. Moreover, our patient was counseled regarding surgery and prognosis of his condition; however, he refused to undergo any surgical procedure. After 9 days of hospitalization, our patient died of aneurismal rupture. Due to religious beliefs, relatives of the deceased refused an autopsy and one was not done.

\section{Discussion}

Pulmonary artery aneurysms constitute $<1 \%$ of aneurysms occurring in the thoracic cavity [29]. The cause could be idiopathic but many medical conditions including congenital heart defects, connective tissue disorders, systemic vasculitides, and infections are often associated with PAA $[3,4,8,9,14,16-24]$. Clinical presentation is invariably nonspecific and roughly depends on the underlying etiology, location, and size of the aneurysm [9]. Owing to its largely vague presentation [4-7], noninvasive imaging techniques are crucial in reaching the diagnosis [8-13]; however, pulmonary angiography remains the gold standard diagnostic modality [2, 8, 19, 21, 23, 30-32]. About $20-60 \%$ of patients with PAA will die from aneurysm rupture while other serious complications including airway compression and intravascular thrombosis are not uncommon [9, 33-38].

Hemoptysis in a tuberculosis (TB) setting is relatively common, usually self-limiting or controlled by anti-TB drugs. Nevertheless, presence of a massive or several episodes of minor hemoptysis in TB is life-threatening, likely originating from the arterial system, and require early and aggressive intervention [39, 40]. Rasmussen's aneurysm is a rare sequalae of pulmonary TB resulting from gradual weakening of the pulmonary artery wall from the adjacent tubercular cavity leading to thinning and pseudoaneurysm formation [36-39]. It has been reported in approximately $5 \%$ of autopsy series involving patients with chronic cavitary tuberculosis [39-44]. Despite absence of clear guidelines for treatment of PAA, several

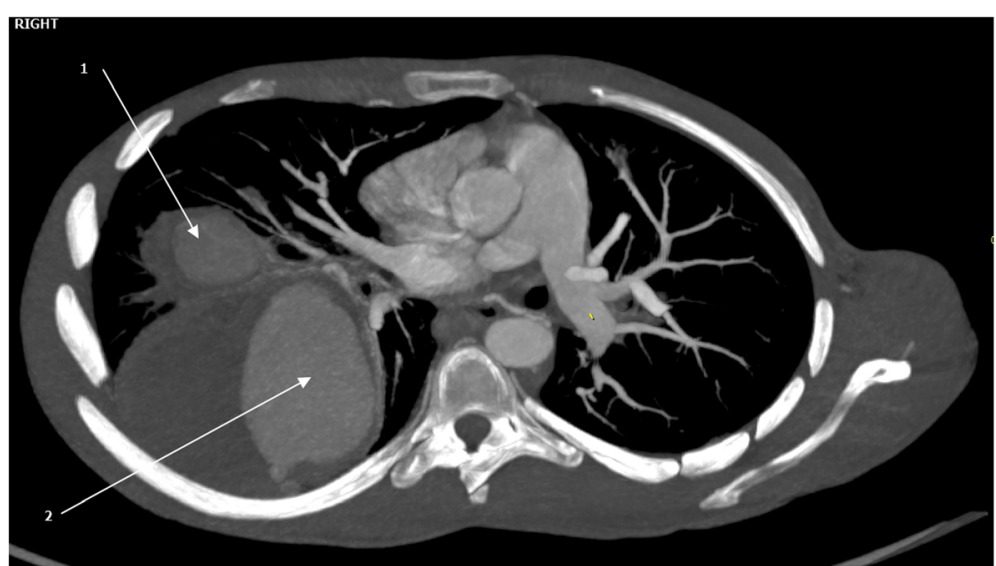

Fig. 3 Computed tomography chest scan (axial and coronal views) showing multiple bilateral pulmonary artery pseudoaneurysms (arrows) with surrounding hematoma 


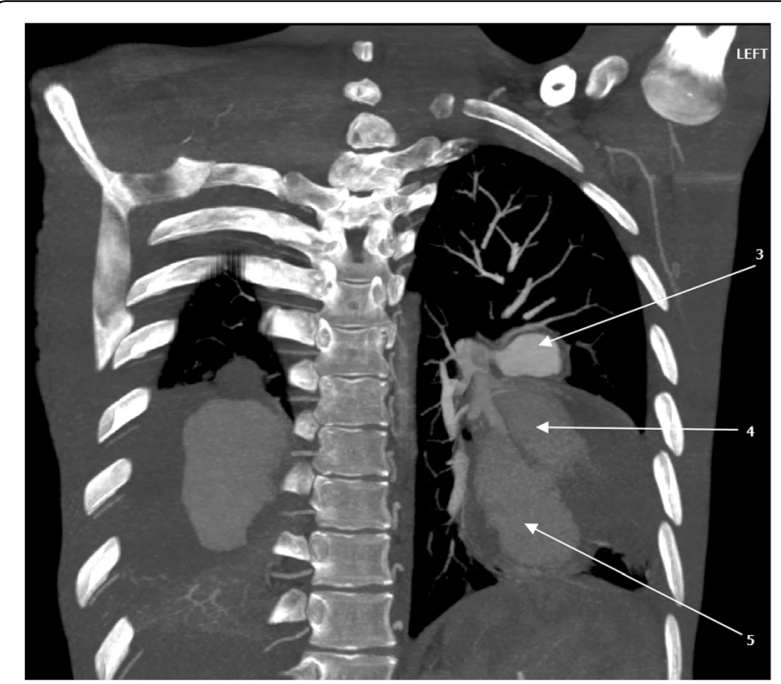

Fig. 4 Computed tomography chest scan (axial and coronal views) showing multiple bilateral pulmonary artery pseudoaneurysms (arrows) with surrounding hematoma

surgical techniques including aneurysmorrhaphy, Dacron graft replacement, pulmonary allograft replacement, and replacement with combination of Dacron prosthesis and stentless bioprosthesis are advocated $[9,19$, $21,28,45,46]$. Furthermore, patients presenting with massive hemoptysis are usually treated with a bronchial artery embolization procedure [47]. However, such an embolization procedure technique requires special care especially in pseudoaneurysms as they are easily prone to rupture with resultant fatal bleeding [39, 43, 47].

Our patient refused to undergo any surgical procedure and consequently died of aneurismal rupture on the

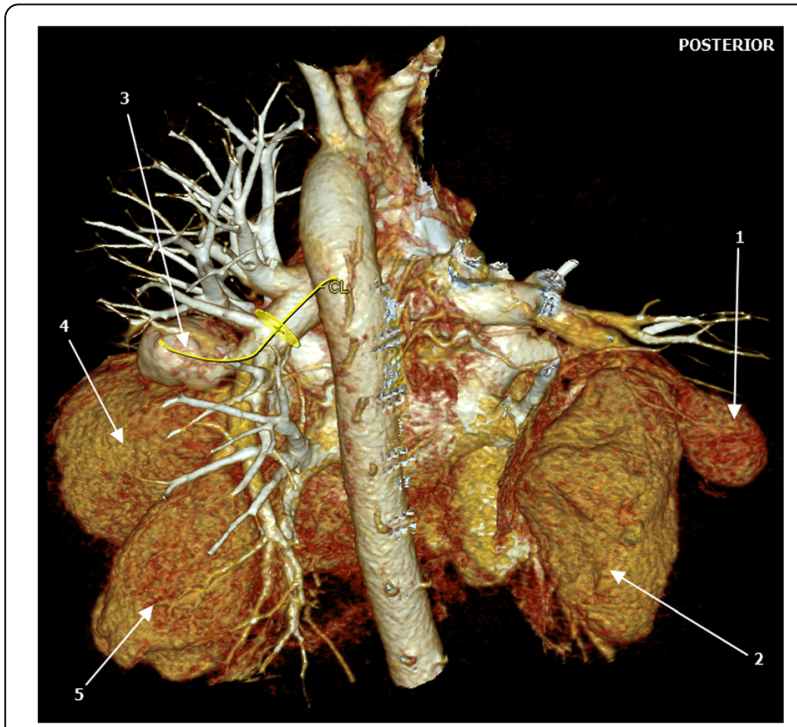

Fig. 5 Volume-rendered computed tomography image showing multiple bilateral pulmonary pseudoaneurysms (arrows) ninth day of hospitalization. Arguably, even if he had opted for surgery, the presence of multiple bilateral large pseudoaneurysms would have potentiated a high risk of fatal bleeding, among other complications, using any surgical technique. Nevertheless, watchful waiting, as in this case, portends a very poor prognosis. To the best of our knowledge, this was the first ever case of TBassociated PAA to be diagnosed and documented in Tanzania. We hope that upon its publication this case will sensitize practitioners to consider and assess for PAA whenever faced by hemoptysis not responding to otherwise routine therapy.

\section{Conclusions}

In conclusion, presence of intractable hemoptysis among TB patients even after completion of an anti-TB course should raise an index of suspicion for PAA. Furthermore, despite its rarity, early recognition and timely surgical intervention is crucial in reducing morbidity and preventing the attributed mortality.

\section{Abbreviations}

CT: Computed tomography; ECG: Electrocardiogram; ECHO: Echocardiography; Hb: Hemoglobin; IVDU: Intravenous drug use; MCH: Mean corpuscular hemoglobin; MCV: Mean corpuscular volume; MRI: Magnetic resonance imaging; $\mathrm{Na}^{+}$: Sodium concentration; PAA: Pulmonary artery aneurysm; PT: Prothrombin time; PTT: Partial thromboplastin time; RDW: Red cell distribution width; RVSP: Right ventricular systolic pressure; STI: Sexually transmitted infections; TB: Tuberculosis

\section{Acknowledgements}

The authors are grateful to the staff of the Jakaya Kikwete Cardiac Institute and Muhimbili National Hospital for their hard work and cooperation in daily patient management.

\section{Funding}

Not applicable

\section{Availability of data and materials}

Not applicable

\begin{abstract}
Authors' contributions
PP and SB took the history and performed physical examinations. FLy HM, $F L W$, and PS performed and interpreted all the imaging modalities. BN, PL, and $\mathrm{MJ}$ gave an expert opinion regarding management of the patient. PP wrote the initial draft of the manuscript. All authors reviewed and contributed to the final version of this case report.
\end{abstract}

Ethics approval and consent to participate

Ethical clearance was granted by the Directorate of Research of the Jakaya Kikwete Cardiac Institute

Consent for publication

Written informed consent was obtained from the patient's next-of-kin for publication of this case report and any accompanying images. A copy of the written consent is available for review by the Editor-in-Chief of this journal.

Competing interests

The authors declare that they have no competing interests.

\section{Publisher's Note}

Springer Nature remains neutral with regard to jurisdictional claims in published maps and institutional affiliations. 


\section{Author details}

'Department of Cardiovascular Medicine, Jakaya Kikwete Cardiac Institute, P.O Box 65141, Dar es Salaam, Tanzania. ${ }^{2}$ Department of Radiology, Muhimbili National Hospital, P.O Box 65000, Dar es Salaam, Tanzania. ${ }^{3}$ Department of Cardiovascular Surgery, Jakaya Kikwete Cardiac Institute, P.O Box 65141, Dar es Salaam, Tanzania. ${ }^{4}$ Department of Radiology and Radiological Science, Medical University of South Carolina, 25 Courteney Drive, MSC 226, Charleston, SC 29425, USA

\section{Received: 15 May 2017 Accepted: 22 June 2017}

\section{Published online: 19 July 2017}

\section{References}

1. Barbour DJ, Roberts WC. Aneurysm of the pulmonary trunk unassociated with intracardiac or great vessel left-to-right shunting. Am J Cardiol. 1987; 59:192-4.

2. Chetty KG, McGovern J, Mahutte CK. Hilar mass in a patient with chest pain. Chest. 1996;109(6):1643-4.

3. Araújo I, Escribano P, Lopez-Gude MJ, et al. Giant pulmonary artery aneurysm in a patient with vasoreactive pulmonary hypertension: a case report. BMC Cardiovasc Disord. 2011;11:64

4. Serasli E, Antoniadou M, Steiropoulos P, et al. Low-pressure pulmonary artery aneurysm presenting with pulmonary embolism: a case series. J Med Case Rep. 2011;5:163.

5. Seguchi M, Wada H, Sakakura K, et al. Idiopathic pulmonary artery aneurysm. Circulation. 2011;124(14):369-70.

6. $\quad$ Ting $P$, Jugdutt BI, Le Tan J. Large pulmonary artery aneurysm associated with Marfan syndrome. Int J Angiol. 2012;19(1):48-50.

7. Deterling Jr RA, Clagett T. Aneurysm of the pulmonary artery; review of the literature and report of a case. Am Heart J. 1947;34:471-99.

8. Nguyen ET, Silva CIS, Seely JM, Chong S, Lee KS, Müller NL. Pulmonary artery aneurysms and pseudoaneurysms in adults: findings at CT and radiography. AJR. 2007;188(2):126-34.

9. Sargur R, Murthy KAS. Pulmonary artery aneurysm - report of a case and review of literature. J Cardiovasc Med Cardiol. 2015;2(1):29-31.

10. Wu WS. Images in cardiovascular medicine. Huge calcified pulmonary arterial aneurysm. Circulation. 2003:107:2280-1.

11. Janssens F, Verswijvel G, Colla P, Smits J, Gubbelmans H, et al. Proximal pulmonary artery aneurysm. JBR-BTR. 2003;86:83-5.

12. Khalil A, Parrot A, Fartoukh $M$, et al. Images in cardiovascular medicine. Large pulmonary artery aneurysm rupture in Hughes-Stovin syndrome: multidetector computed tomography pattern and endovascular treatment. Circulation. 2006;114:380-1.

13. Cherwek $\mathrm{H}$, Amundson S. Images in clinical medicine. Pulmonary-artery aneurysm. N Engl J Med. 2003:348:e1.

14. Singh V, Khare R, Chandra S, Dwivedi SK. Giant pulmonary artery aneurysm in a patient with rheumatic mitral stenosis. Heart Views. 2014;15:89-92.

15. Mayoral-Campos V, de Benito-Arévalo JL, Varea-Sanz MA. Pulmonary artery aneurysm. Arch Bronconeumol. 2013;49:551-2.

16. Baztarrica GP, Bevacqua F, Porcile R. Pulmonary artery aneurysm. Rev Esp Cardiol. 2010:63:240-1.

17. Vistarini N, Aubert S, Gandjbakhch I, Pavie A. Surgical treatment of a pulmonary artery aneurysm. Eur J Cardiothorac Surg. 2007;31(6):1139-41.

18. Garcia A, Byrne JG, Bueno R, et al. Aneurysm of the main pulmonary artery. Ann Thorac Cardiovasc Surg. 2008;14:399-401.

19. Shih HH, Kang PL, Lin CY, Lin YH. Main pulmonary artery aneurysm. J Chin Med Assoc. 2007:70(10):453-5.

20. Shankarappa RK, Moorthy N, Chandrasekaran D, Nanjappa MC. Giant pulmonary artery aneurysm secondary to primary pulmonary hypertension. Tex Heart Ins J. 2010;37:244-5.

21. Fazlinejad A, Vojdanparast M, Esfehani RJ, et al. Giant idiopathic pulmonary artery aneurysm: an interesting incidental finding. Case Rep Vasc Med. 2014; 2014:251373.

22. Hammad AM, Al-Qahtani SM, Al-Zahrani MA. Huge pulmonary artery aneurysm. Can Respir J. 2009;16(3):93-5

23. Theodoropoulos P, Ziganshin BA, Tranquilli M, Elefteriades JA. Pulmonary artery aneurysms: four case reports and literature review. Int J Angiol. 2013; 22(3):143-8.

24. Chiu P, Irons $M$, van de Rijn $M$, et al. Giant pulmonary artery aneurysm in a patient with Marfan syndrome and pulmonary hypertension. Circulation. 2016;133:1218-21.
25. Muthialu N, Raju V, Muthubaskaran V, et al. Idiopathic pulmonary artery aneurysm with pulmonary regurgitation. Ann Thoracic Surg. 2010;90(6): 2049-51.

26. van Rens MTM, Westermann CJJ, Postmus PE, Schramel FM. Untreated idiopathic aneurysm of the pulmonary artery; long-term follow-up. Respir Med. 2000;94(4):404-5.

27. Arslan S, Kalkan ME, Gündoǧdu F, Kantarci M. Idiopathic pulmonary artery aneurysm in a patient presenting with chest pain. Turk Kardiyoloji Dernegi Arsivi. 2009:37(4):253-5.

28. Agarwal S, Chowdhury UK, Saxena A, et al. Isolated idiopathic pulmonary artery aneurysm. Asian Cardiovasc Thorac Ann. 2002;10(2):167-9.

29. Ritter $\mathrm{CO}$, Weininger $\mathrm{M}$, Machann $\mathrm{M}$, et al. Non-invasive imaging in a rare case of main pulmonary artery aneurysm. Respir Med. 2008;102(5):790-2.

30. Lopez-Candales A, Kleiger RE, Aleman-Gomez J, Kouchoukos NT, Botney MD. Pulmonary artery aneurysm: review and case report. Clin Cardiol. 1995; 18:738-40.

31. Bartter T, Irwin RS, Nash G. Aneurysms of the pulmonary arteries. Chest. 1988:94:1065-75.

32. Nair KS, Cobanoglu AM. Idiopathic main pulmonary artery aneurysm. Ann Thorac Surg. 2001;71:1688-90.

33. Ungaro R, Saab S, Almond CH, Kumar S. Solitary peripheral pulmonary artery aneurysms. Pathogenesis and surgical treatment. J Thorac Cardiovasc Surg. 1976;71(4):566-71

34. Butto F, Lucas JRV, Edwards JE. Pulmonary arterial aneurysm. A pathologic study of five cases. Chest. 1987;91(2):237-41.

35. Sakuma M, Demachi J, Suzuki J, Nawata J, Takahashi T, Shirato K. Proximal pulmonary artery aneurysms in patients with pulmonary artery hypertension: complicated cases. Intern Med. 2007:46(21):1789-93.

36. Hernández V, Ruiz-Cano MJ, Escribano P, Sánchez MA. Complications of proximal pulmonary artery aneurysm in patients with severe pulmonary arterial hypertension. Rev Esp Cardiol. 2010;63(5):617-8.

37. Kussman BD, Geva T, McGowan FX. Cardiovascular causes of airway compression. Paediatr Anesth. 2004;14:60-74.

38. Arena V, De Giorgio F, Abbate A, Cappelli A, De Mercurio D, Carbone A. Fatal pulmonary arterial dissection and sudden death as initial manifestation of primary hypertension case report. Cardiovasc Pathol. 2004;13:349-71.

39. Chatterjee K, Colaco B, Colaco C, et al. Rasmussen's aneurysm: a forgotten scourge. Respir Med Case Rep. 2015;16:74-6.

40. Keeling AN, Costello R, Lee MJ. Rasmussen's aneurysm: a forgotten entity? Cardiovasc Interv Radiol. 2008;31(1):196-200.

41. Santelli ED, Katz DS, Goldschmidt AM, Thomas HA. Embolization of multiple Rasmussen aneurysms as a treatment of hemoptysis. Radiology. 1994;193: 396-8.

42. Remy J, Smith M, Lemaitre L, Marache P, Fournier E. Treatment of massive hemoptysis by occlusion of a Rasmussen aneurysm. Am J Roentgenol. 1980; 135:605-6.

43. Shih SY, Tsai IC, Chang YT, et al. Fatal haemoptysis caused by a ruptured Rasmussen's aneurysm. Thorax. 2011;66(6):553-4.

44. Raviglione MC, O'Brien RJ. Tuberculosis. In: Kasper DL, Braunwald E, Fauci AS, Hauser SL, Longo DL, Jameson L, editors. Harrison's principles of internal medicine. 16th ed. New York: McGraw Hill; 2005. p. 953-66.

45. Kuwaki K, Morishita K, Sato H, et al. Surgical repair of the pulmonary trunk aneurysm. Euro J Cardiothoracic Surg. 2000;18(5):535-9.

46. Casselman F, Deferm $H$, Peeters $P$, Vanermen $H$. Aneurysm of the left pulmonary artery: surgical allograft repair. Ann Thorac Surg. 1995;60:1423-5.

47. Sapra R, Sharma G, Minz AK. Rasmussen's aneurysm: a rare and forgotten cause of hemoptysis. Indian Heart J. 2015:67 Suppl 3:53-6. 